\title{
Effects of isometric exercise and increased arterial impedance on left ventricular function in severe aortic valvular stenosis ${ }^{1,2}$
}

\author{
- NAJAM AWAN, LOUIS A. VISMARA, RICHARD R. MILLER, \\ ANTHONY N. DEMARIA, AND DEAN T. MASON \\ From the Section of Cardiovascular Medicine, Departments of Medicine and Physiology, University of \\ California, School of Medicine, Davis, California, U.S.A.
}

Since critical aortic stenosis imposes severe obstruction to cardiac outflow, the peripheral vascular determinants of left ventricular impedance in this condition remain uncertain. Thus, the systemic arterial and left ventricular haemodynamic responses to acute circulatory interventions were evaluated during cardiac catheterisation in 10 patients with severe aortic stenosis (valve area $0.40 \mathrm{~cm}^{2} / \mathrm{m}^{2}$ ). Sustained isometric handgrip exercise increased systemic vascular resistance to 1278 dynes $\mathrm{s} \mathrm{cm}^{-5}$ and arterial blood pressure to peak systolic $143 \mathrm{mmHg}$ (mean 94), which were significantly $(P<0.01)$ greater than control (systemic vascular resistance 1110; BP peak systolic 122; BP mean 80). Isometric handgrip exercise was also accompanied by concordant changes in left ventricular pressures $(P<0 \cdot 01)$ of peak systolic from 191 to $213 \mathrm{mmHg}$ and end-diastolic from 16 to $23 \mathrm{mmHg}$; cardiac output $(5.62 \mathrm{l} / \mathrm{min})$ and peak systolic left ventricular aortic gradient $(69 \mathrm{mmHg})$ were unchanged $(P>0.05)$. In 7 of these patients intravenous phenylephrine infusion $(2.7$ to $6.0 \mu \mathrm{g} / \mathrm{min})$ produced the following responses similar $(P>0.05)$ to isometric handgrip exercise: increases $(P<0.01)$ in systemic vascular resistance to $1549, B P$ to peak systolic 150 and mean 97 , and left ventricular pressures to peak systolic 211 and end-diastolic $22(P<0.02)$ without alterations in cardiac output or peak systolic LV-aortic gradient; isometric handgrip exercise was accompanied by an increase $(P<0.01)$ in contractile state indices (peak dp/dt 1882 to $2580 \mathrm{mmHg} / \mathrm{s}$; Vmax 4.28 to $6.43 \mathrm{circ} / \mathrm{s}$ ) and rise in heart rate (72 to $82 \mathrm{bpm}$ ) while these variables remained constant $(P>0.05)$ with phenylephrine. Therefore, augmentation of arterial resistance increased left ventricular impedance resulting in abnormalities of cardiac haemodynamics despite the presence of pronounced valvular obstruction. These observations are of potential importance in the pathogenesis of sudden death in severe aortic stenosis and provide therapeutic insight in emergency medical management of ventricular dysfunction in this condition.

Recent investigations have emphasised the importance of vascular impedance in the regulation of left ventricular function (Mason, 1973; Miller et al., 1975; Williams et al., 1975). Thus decrease in systemic arterial resistance with a variety of peripheral vasodilator agents has been shown to enhance pump performance in patients with cardiac dysfunction with coronary heart disease, valvular and ischaemic mitral regurgitation, and aortic valvular regurgitation (Majid et al., 1971; Franciosa et al.,

${ }^{1}$ Presented in part at the 48th Scientific Sessions of The American Heart Association, Anaheim, California, 20 November 1975.

'Supported in part by a Research Program Project Grant from The National Heart and Lung Institute, NIH, Bethesda, Maryland, and Research Grants from California Chapters of The American Heart Association, Dallas, Texas, U.S.A.

Received for publication 14 September 1976
1972; Chatterjee et al., 1973; Chatteriee and Swan, 1974; Cohn et al., 1974; Miller et al., 1975, 1976a, b). In these clinical settings afterload reduction results in improved left ventricular performance by increasing depressed ejection fraction and raising effective stroke output concomitant with lessened myocardial oxygen requirements. However, since severe valvular aortic stenosis poses a fixed obstruction to left ventricular ejection which might obviate the cardiac response to peripheral circulatory changes, the relation between ventricular function and systemic vascular dynamics in this condition is unknown. Therefore, to evaluate the control and determinants of left ventricular performance in aortic stenosis, the present study was undertaken to assess the haemodynamic response to acute rises 
in arterial impedance in this form of systolic pressure overload.

\section{Subjects and methods}

\section{PATIENTS}

The data for this study were obtained from 10 consecutive patients with isolated critical valvular aortic stenosis undergoing diagnostic cardiac catheterisation and coronary arteriography. All patients were without angiographic evidence of other valvular dysfunction, coronary arterial obstruction, or segmental ventricular dyssynergy. There were 8 men and 2 women whose ages ranged from 43 to 72 years (mean 58 years). Clinical symptoms included cerebral ischaemia, 6 patients; cardiac decompensation, 3 patients; and angina pectoris, 7 patients. Functional classification by the criteria of the New York Heart Association was Class I, 5 patients; Class II, 3 patients; and Class III, 2 patients. All patients voluntarily gave informed consent for the present study.

\section{CARDIAC CATHETERISATION}

Each of the patients underwent diagnostic right and retrograde left heart catheterisation without systemic premedication. All left ventricular pressure recordings were obtained using the high-fidelity micromanometer-tip catheter (Millar Instruments, Inc., Houston, Texas) possessing a frequency response of $20 \mathrm{kHz}$. The first derivative of left ventricular pressure (dp/dt) was obtained by an electronic differentiator with a linear amplitude response above $500 \mathrm{~Hz}$. Lead II of the external electrocardiogram was recorded. Cardiac output was measured in duplicate by the indicator dilution technique using indocyanine green dye injected into the left ventricle with brachial arterial sampling. The brachial artery phasic and mean pressures, obtained by the No. 18 Longdwell needle, were shown to be the same as the central aortic pressures in each patient. Systemic arterial pressure was recorded using the Statham P23Db transducer which enabled frequent measurements of the transaortic valvular gradient. The aortic valve area, calculated by the Gorlin formula (Gorlin and Gorlin, 1951), was the same in each individual using either the simultaneous left ventricular-brachial artery or left ventricular-ascending aortic pressure gradients.

\section{ISOMETRIC HAND GRIP}

All patients were familiarised with the handgrip dynamometer (Asimow Engineering Co., Los Angeles, California) and its utilisation before catheterisation. After the recording of control haemodynamic data, the patients exerted maximum instantaneous force on the dynamometer which was followed by sustained grasp at 30 per cent of their peak handgrip exertion for a total period of 5 minutes. Normal ventilation was maintained during the isometric exercise period with avoidance of the Valsalva manoeuvre. All cardiocirculatory measurements were repeated during the final minute of sustained static exercise.

\section{PHENYLEPHRINE INFUSION}

After the cessation of isometric exercise, haemodynamics promptly returned to the control state, which were allowed to be maintained for at least an additional 10 minutes. Subsequently in 7 of the 10 patients phenylephrine was administered intravenously (range 2.7 to $6.0 \mu \mathrm{g} / \mathrm{min}$; mean $3.0 \mu \mathrm{g} / \mathrm{min}$ ) to reproduce the same rise in systemic arterial pressure as occurred during isometric handgrip exercise. Patients were stabilised at this increased level of systemic arterial pressure by constant phenylephrine infusion for 5 minutes, during the final minute of which cardiac and systemic haemodynamics were again assessed.

\section{HAEMODYNAMIC MEASUREMENTS}

The following values were measured or calculated during the periods of control, isometric exercise, and phenylephrine infusion: cardiac index; stroke index; left ventricular stroke work index (Snell and Luchsinger, 1965); systemic vascular resistance (Miller et al., 1975); and tension-time index (Sarnoff et al., 1958). Further, left ventricular forcevelocity relations were calculated from 5 consecutive contractions using the high-fidelity recordings of ventricular pressure and simultaneous $\mathrm{dp} / \mathrm{dt}$ at $5 \mathrm{~ms}$ intervals during isovolumic systole (Mason et al., 1971). Contractile element velocity (Vce) was determined by the Maxwell three component muscle model and the Vmax contractility index was estimated by extrapolation of the Vce-developed pressure curve to zero load by means of a polynomial regression equation (Mason et al., 1970). In addition, left ventricular peak dp/dt (Mason, 1969) was obtained. All data and the interventions were carried out before contrast angiography. Student's $t$ test for paired data was used for analysis of statistical significance.

\section{Results}

\section{CONTROL HAEMODYNAMICS}

Control haemodynamic data are presented in the Table. All patients had critical aortic stenosis as indicated by pronounced transvalvular gradients (average peak systolic $69 \mathrm{mmHg}$; range 44 to 123) with severe reduction of aortic valve area index (average: 
Table Cardiocirculatory changes during isometric exercise and phenylephrine infusion

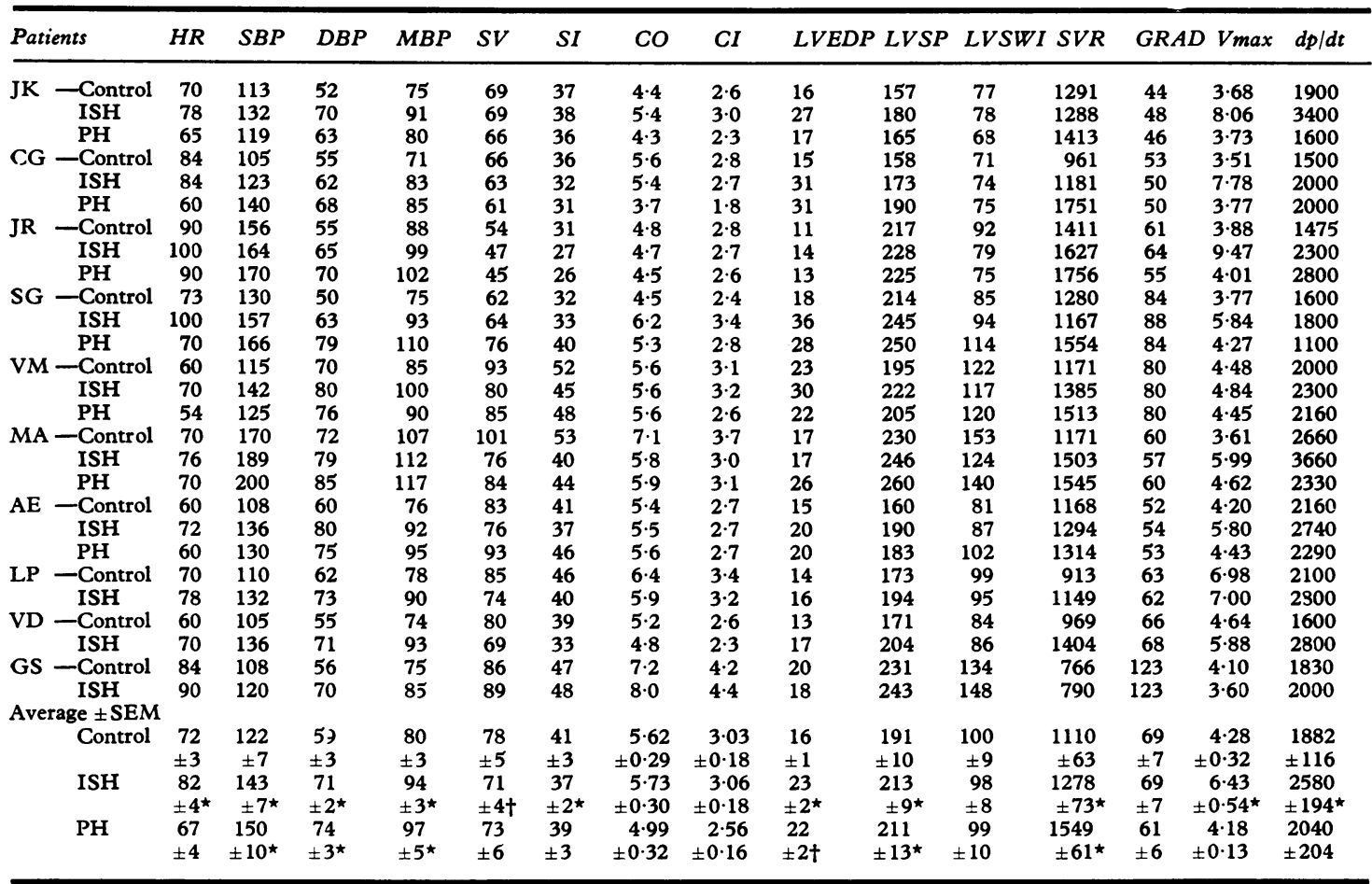

Abbreviations: ISH, isometric handgrip exercise; PH, phenylephrine; HR, heart rate, beats/min; SBP, systolic blood pressure (mmHg); DBP, diastolic blood pressure (mmHg); MBP, mean blood pressure (mmHg); SV, stroke volume (ml); SI, stroke index, $\mathrm{ml} / \mathrm{m}^{2}$; $\mathrm{CO}$, cardiac output, $1 / \mathrm{min}$; CI, cardiac index, $1 / \mathrm{min}$ per $\mathrm{m}^{2}$; LVEDP, left ventricular end-diastolic pressure (mmHg); LVSP, left ventricular peak systolic

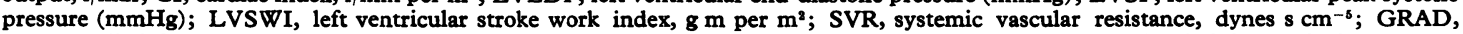
peak systolic left ventricular-aortic gradient $(\mathrm{mmHg}) ; \mathrm{Vmax}$, circumferences/s; dp/dt, maximum rate of isovolumic left ventricular pressure rise $(\mathrm{mmHg} / \mathrm{s}) ;{ }^{\star} \mathrm{P}<0.01 ; \dagger, \mathrm{P}<0.02$.

$0 \cdot 40 \mathrm{~cm}^{2}$ per $\mathrm{m}^{2}$; range: $0 \cdot 25$ to $\left.0 \cdot 49\right)$. There were mild to moderate rises in left ventricular enddiastolic pressure in 9 of the 10 individuals (average $16 \mathrm{mmHg}$ ). Cardiac index was normal in all but one patient in whom it was minimally decreased (average $3.031 / \mathrm{min}$ per $\mathrm{m}^{2}$ ). Left ventricular ejection fraction was greater than 60 per cent in 6 patients and above 40 per cent in the remaining 4 subjects (average 62 per cent).

\section{ISOMETRIC HANDGRIP}

The cardiocirculatory responses induced by sustained isometric exertion are shown in the Table. Handgrip exercise resulted in significant rises $(P<0.01)$ in systolic, diastolic, and mean systemic arterial pressures. Since cardiac index remained unaltered $(P>0.05)$, total systemic vascular resistance rose substantially from 1110 to 1278 dynes sec $\mathrm{cm}^{-5}(P<0.01)$. There were concordant increases in the systemic arterial and left ventricular systolic pressures; thereby the peak systolic gradient across the aortic valve remained constant $(P>0.05)$
(Fig. 1A). Further, as indicated in Fig. 1B, in each patient there was a close correlation between the rises in both the left ventricular and systemic arterial systolic pressures during isometric exertion $(r=0.94)$. Static handgrip resulted in a slight rise in heart rate $(P<0.05)$ (Fig. 2A); stroke index declined $(\mathrm{P}<0.01)$ (Fig. 2B); while ventricular stroke work remained unchanged $(P<0.05)$. These haemodynamic changes were accompanied by a significant rise in left ventricular end-diastolic pressure $(\mathrm{P}<0.01)$ (Fig. 2C) and a pronounced rise in the tension-time index $(P<0.01)$ (Fig. 2D).

\section{PHENYLEPHRINE INFUSION}

All haemodynamic data recorded after termination of isometric exercise and immediately preceding phenylephrine infusion were the same as those in the initial control period for each patient (Table). Phenylephrine administration provoked substantial peripheral vasoconstriction as indicated by the augmentations in systemic blood pressure $(P<0.01)$ and systemic vascular resistance $(P<0.01)$. Thereby 

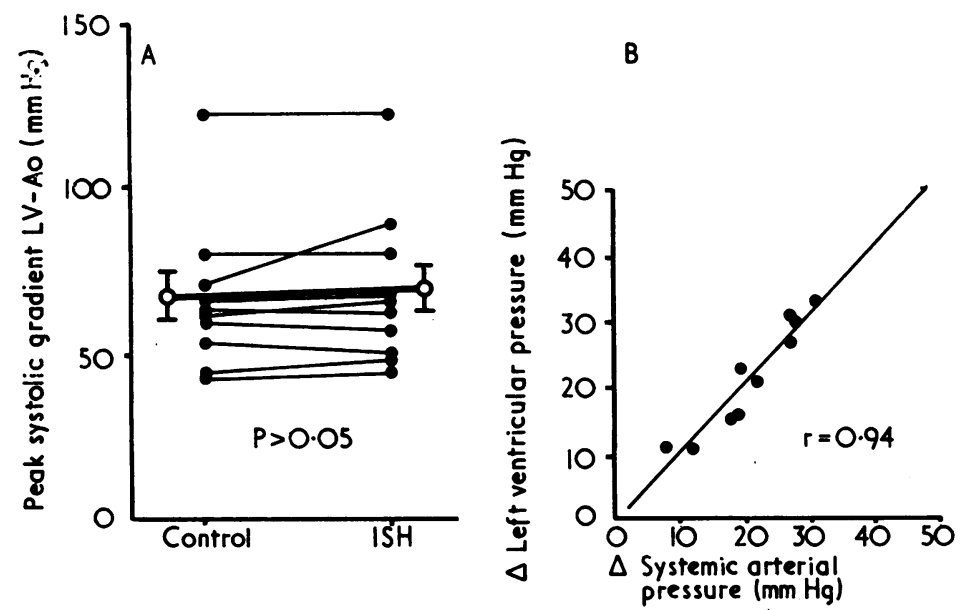

Fig. 1 Left ventricular ( $L V)$ response to isometric exertion (ISH) in severe aortic stenosis. Panel $A$ indicates that no change occurred in peak systolic left ventricular-aortic (Ao) pressure gradient during ISH. Panel $B$ shows the relation between increase in arterial and increase in $L V$ peak systolic pressure during ISH. Thus, increased systemic arterial resistance and blood pressure imposed additional aortic impedance and afterload burden on the left ventricle despite the presence of critical aortic stenosis.

this alpha-adrenergic agonist resulted in alterations of peripheral circulatory dynamics which were similar $(P>0.05)$ to the systemic arterial response provoked by isometric exertion. Complete data on the cardiac response to phenylephrine infusion are provided in the Table. Though the changes in left
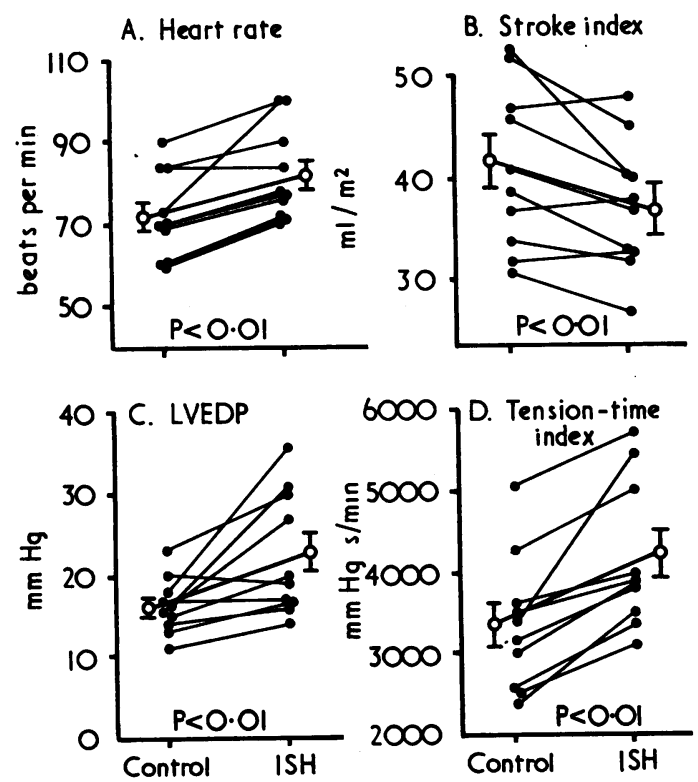

Fig. 2 Left ventricular response to ISH in aortic stenosis. Panel $A$ shows that static exertion provoked a significant rise in heart rate. Since cardiac output remained unchanged, stroke index decreased (Panel B). The haemodynamic burden imposed by ISH on left ventricular function is shown in the lower panels; left ventricular end-diastolic pressure (LVEDP) (Panel C) and tension-time index (Panel D) increased in all patients. ventricular pressures (peak systolic, end-diastolic, and transaortic peak systolic gradient) did not differ between phenylephrine and handgrip stress, the response to the drug infusion was not associated with alteration $(P>0.05)$ in either heart rate or left ventricular contractility indices.

\section{Discussion}

The present investigation emphasises the integral relation between peripheral circulatory dynamics and cardiac pump performance even in the presence of aortic stenosis. Specifically our findings document that an acute rise in systemic vascular resistance accompanied by a rise in arterial blood pressure imposes a substantial burden on left ventricular function despite the presence of critical obstruction to aortic outflow. Therefore, an important observation shown in the Table and Fig. 1 is that in aortic stenosis left ventricular impedance is determined by systemic arterial resistance as well as the fixed valvular obstruction.

This investigation also provides an understanding of the cardiocirculatory changes which occur with static exercise in critical aortic stenosis. Though other studies have measured the cardiac response to isometric exertion in a number of clinical conditions ( $\mathrm{Lind}$ and $\mathrm{McNicol}, 1968$; Lind, 1970; Helfant et al., 1971; Krayenbuehl et al., 1972; Stefadouros et al., 1974), the effects of this intervention in patients with aortic stenosis have not been assessed previously. Since the haemodynamic consequences of isometric exercise are influenced by the extent and duration of sustained contraction, rather than the site or total mass of the active skeletal muscle (Donald et al., 1967), the isometric procedure used in this study provided a 
potent form of static stress (Lind and McNicol, 1967). In normal subjects sustained contraction greater than 15 per cent of the voluntary maximum has been shown to produce a consistent cardiac response which includes a pronounced rise in systemic arterial blood pressure, increased heart rate, and raised cardiac output while the systemic vascular resistance remains unchanged (Donald et al., 1967). Though the exact mechanisms of these cardiovascular changes have not been clarified, studies by Lind and associates have implicated a centrally mediated neurocirculatory mechanism by which the high systemic arterial pressure provides perfusion of the active skeletal muscle despite mechanical compression of the vascular bed in the involved musculature (Donald et al., 1967; Lind and McNicol, 1967). Thus, the normal left ventricle respor.ds to isometric stress with an increase in stroke work index using enhanced inotropic activity while cardiac preload remains constant (Stefadouros et al., 1974).

In contrast, our present investigation shows that isometric exertion produces a deleterious effect on left ventricular performance in patients with severe aortic stenosis. Therefore, as indicated by the rise in cardiac tension-time index and the other variables related to myocardial energetics (Fig. 2), left ventricular oxygen requirements were shown to be considerably greater during handgrip exertion than in the control period. The major factors responsible for this rise in cardiac oxygen demands include the augmentation in systemic vascular resistance and arterial blood pressure combined with a faster heart rate. Furthermore, the increase in cardiac preload and the concomitant enhancement of the indices of left ventricular contractility also principally contributed to the greater myocardial oxygen needs. Nevertheless, since cardiac stroke index declined and ventricular stroke work failed to rise appropriately, static exertion resulted in impaired ventricular performance and efficiency.

These haemodynamic changes are consistent with previous studies of static exertion in patients with ventricular dysfunction unrelated to aortic stenosis (Amende et al., 1972). For example, the study of patients with ventricular volume overload or coronary artery disease by Amende and colleagues showed that sustained handgrip was accompanied by a significant rise in left ventricular end-diastolic pressure without a change in stroke work index (Amende et al., 1972). Similarly, this same response was also observed in patients with heart disease by Kivowitz et al. (1971). In addition, these investigators were able to correlate the isometric-induced haemodynamic abnormalities with the severity of clinical functional impairment, and thereby concluded that isometric handgrip provided a simple haemodynamic assessment of left ventricular contractile reserve.

Since isometric exertion provokes a number of simultaneous cardiovascular responses (Donald et al., 1967; Lind and McNicol, 1967; Amende et al., 1972; Stefadouros et al., 1974), it was the intent of the present study to evaluate further the left ventricular response to acute isolated changes in peripheral resistance in aortic stenosis. The dose regimen of phenylephrine administered provided peripheral alpha-adrenergic receptor stimulation without direct pharmacological cardiac action (Eckstein and Abboud, 1962; Kivowitz et al., 1971). Infusion of this agent in 7 of our patients resulted in a rise in systemic arterial pressure and vascular resistance to levels that were similar to those provoked by isometric exertion (Table). Haemodynamic measurements during constant phenylephrine administration indicated that the left ventricular systolic pressure and transaortic gradient responses were similar to those produced by hand grip exercise. Thus, this pharmacological intervention provides confirmatory evidence that ventricular function in critical aortic stenosis is directly influenced by changes in systemic vascular impedance.

It is important to emphasise the potential clinical implications of the haemodynamic responses observed herein. Since isometric exertion caused acute depression in ventricular performance in our aortic stenosis patients, these data provide a potential pathophysiological explanation for sudden death which is a recognised clinical hallmark in this condition and has been described during static exertion (Schwartz et al., 1969). Thus, the combination of increased myocardial oxygen requirements and reduced stroke index during isometric exertion may result in further imbalance of the already jeopardised myocardial oxygen supply-todemand relation, with resultant fatal ventricular arrhythmias. Further, rapidly occurring death in this clinical condition has also been attributed to a progressive low output state which precedes terminal arrhythmias (Schwartz et al., 1969). Since even the isometric exertion of short duration conducted in this study induced pronounced haemodynamic impairment, it is possible that even more severe static exertion might result in a deleterious cycle of rising systemic impedance with consequent failing cardiac output. Furthermore, the data also provide important therapeutic insights for additional evaluation. Since the present study establishes the interrelation between left ventricular and peripheral vascular dynamics in critical aortic stenosis, reduction in systemic impedance by pharmacological means may provide a temporary 
but potentially life-saving medical adjunct for improving depressed cardiac performance which could afford additional time for definitive surgical therapy in this condition.

\section{References}

Amende, I., Krayenbuehl, H. P., Rutishauser, W., and Wirz, P. (1972). Left ventricular dynamics during handgrip. British Heart Fournal, 34, 688-695.

Chatterjee, K., Parmley, W. W., Ganz, W., Forrester, J., Walinsky, P., Crexells, C., and Swan, H. J. C. (1973). Hemodynamic and metabolic responses to vasodilator therapy in acute myocardial infarction. Circulation, 48, 1183-1193.

Chatterjee, K., and Swan, H. J. C. (1974). Vasodilator therapy in acute myocardial infarction. Modern Concepts in Cardiovascular Disease, 43, 119-124.

Cohn, J. N., Mathew, K. J., Franciosa, J. A., and Snow, J. A. (1974). Chronic vasodilator therapy in the management of cardiogenic shock and intractable left ventricular failure. Annals of Internal Medicine, 81, 777-780.

Donald, K. W., Lind, A. R., McNicol, G. W., Humphreys, P. W., Taylor, S. H., and Staunton, H. P. (1967). Cardiovascular responses to sustained (static) contractions. Circulation Research, 20 and 21, Suppl. I, I-15-30.

Eckstein, J. W., and Abboud, F. M. (1962). Circulatory effects of sympathomimetic amines. American Heart fournal, 63, 119-135.

Franciosa, J. A., Guiha, N. H., Limas, C. J., Rodriguera, E., and Cohn, J. N. (1972). Improved left ventricular function during nitroprusside infusion in acute myocardial infarction. Lancet, 1, 650-654.

Gorlin, R., and Gorlin, S. G. (1951). Hydraulic formula for calculation of the area of the stenotic mitral valve, other cardiac valves, and central circulatory shunts. American Heart fournal, 41, 1-29.

Helfant, R. H., DeVilla, M. A., and Meister, S. G. (1971). Effect of sustained isometric handgrip exercise on left ventricular performance. Circulation, 44, 982-993.

Kivowitz, C., Parmley, W. W., Donoso, R., Marcus, H., Ganz, W., and Swan, H. J. C. (1971). Effects of isometric exercise on cardiac performance. The grip test. Circulation, 44, 994-1002.

Krayenbuehl, H. P., Rutishauser, W., Schoenbeck, M., and Amende, I. (1972). Evaluation of left ventricular function from isovolumic pressure measurements during isometric exercise. American fournal of Cardiology, 29, 323-330.

Lind, A. R. (1970). Editorial. Cardiovascular responses to static exercise (isometrics, anyone?). Circulation, 41, 173176.

Lind, A. R., and McNicol, G. W. (1967). Muscular factors which determine the cardiovascular responses to sustained and rhythmic exercise. Canadian Medical Association Fournal, 96, 706-713.

Lind, A. R., and McNicol, G. W. (1968). Cardiovascular responses to holding and carrying weights by hand and by shoulder harness. Fournal of Applied Physiology, 25, 261267.
Majid, P. A., Sharma, B., and Taylor, S. H. (1971). Phentolamine for vasodilator treatment of severe heart failure. Lancet, 2, 719-724.

Mason, D. T. (1969). Usefulness and limitations of the rate of rise of intraventricular pressure $(\mathrm{dp} / \mathrm{dt})$ in the evaluation of myocardial contractility in man. American fournal of Cardiology, 23, 516-527.

Mason, D. T. (1973). Regulation of cardiac performance in clinical heart disease. American fournal of Cardiology, 32, 437-448.

Mason, D. T., Braunwald, E., Covell, J. W., Sonnenblick, E. H., and Ross, J., Jr. (1971). Assessment of cardiac contractility. The relation between the rate of pressure rise and ventricular pressure during isovolumic systole. Circulation, 44, 47-58.

Mason, D. T., Spann, J. F., Jr., and Zelis, R. (1970). Quantification of the contractile state of the intact human heart. Maximal velocity of contractile element shortening determined by the instantaneous relation between the rate of pressure rise and pressure in the left ventricle during isovolumic systole. American fournal of Cardiology, 26, 248257.

Miller, R. R., Vismara, L. A., DeMaria, A. N., Salel, A. F., amd Mason, D. T. (1976a). Afterload reduction therapy with nitroprusside in severe aortic regurgitation: improved cardiac performance and reduced regurgitation volume. American fournal of Cardiology, 38, 564-567.

Miller, R. R., Vismara, L. A., Williams, D. O., Salel, A. F., Odom, R., and Mason, D. T. (1976b). Effects of nitroprusside on myocardial energetics and coronary blood flow during pacing-induced ischemia in patients with coronary heart disease. American fournal of Cardiology, 37, 156.

Miller, R. R., Vismara, L. A., Zelis, R., Amsterdam, E. A., and Mason, D. T. (1975). Clinical use of sodium nitroprusside in chronic ischemic heart disease. Circulation, 51, 328-336.

Sarnoff, S. J., Braunwald, E., Welch, G. H., Jr., Case, R. B., Stainsby, W. N., and Macruz, R. (1958). Hemodynamic determinants of oxygen consumption of the heart with special reference to the tension-time index. American fournal of Physiology, 192, 148-156.

Schwartz, L. S., Goldfischer, J., Sprague, G. J., and Schwartz, S. P. (1969). Syncope and sudden death in aortic stenosis. American fournal of Cardiology, 23, 647-658.

Snell, R. E., and Luchsinger, P. C. (1965). Determination of the external work and power of the left ventricle in intact man. American Heart fournal, 69, 529-537.

Stefadouros, M. A., Grossman, W., El-Shahawy, M., Stefadourous, F., and Witham, A. C. (1974). Noninvasive study of effect of isometric exercise on left ventricular performance in normal man. British Heart fournal, 36, 988-995.

Williams, D. O., Amsterdam, E. A., and Mason, D. T. (1975). Hemodynamic effects of nitroglycerin in acute myocardial infarction: decrease in preload at the expense of cardiac output. Circulation, 51, 421-427.

Requests for reprints to Professor Dean T. Mason, Section of Cardiovascular Medicine, University of California, School of Medicine, Davis, California 95616, U.S.A. 